\title{
ICT Based Model: Teaching EFL through Online
}

\section{Courses}

\author{
Dr. Boumediene Houda , Dr. Bouakkaz Mustapha \\ University of Laghouat, Algeria
}

\begin{abstract}
Teaching English as a foreign language has become a challenge due to the variety of techniques and methods of teaching as well as the diversity of learners' motivations and interests for learning. Therefore, instructors have to think about current ways to incorporate new strategies in order to promote their teaching process and reach their teaching goals. For this reason, the integration of Information Communication Technology (ICT) especially Online Courses (OC) became widely spread in so many fields including language learning/teaching and more particularly teaching literature. The latter represents that the use of OC helps in understanding of most of the difficult literary texts. Thus, the present study was conducted to evaluate technology-based instruction using OC as an educational tool in learning /teaching EFL literature to Second-year students at the University of Amar Thelidji, the specific objectives include evaluating students' outcomes and attitudes toward the incorporation of $\mathrm{OC}$ in the learning process. To attain the aim of the experimental study two research instruments were used, an experiment with second year students followed by two online questionnaires addressed to 9 teachers and 45 second year students. The findings of the study show that the integration of OC made a suitable tool for promoting learning literature and support the argument which suggests that learners have profited from using OC and they are getting more involved in the experience. Also, this tool enables both teachers to integrate online content and activities with face to face teaching, and learners to facilitate and reinforce literature studies. Based on this study, the integration of OC in literature class is a starting point for further research in blending OC in traditional settings to achieve a
\end{abstract}


successful implementation of online content in a way that it facilitates the learning/teaching process.

Key - words: Literature, online courses, OC, integration, ICT.

\section{Introduction}

The outstanding technological development has already had a conversional impact on most aspects of modern life, work, and education, and Higher Education cannot exempt from this process. In that respect, educational levels are constantly changing, and they need to be aligned with current trends in modern society to treat the conflicts of various technologies.

The alignment of Higher Education with the technological world was resulted in offering the possibility of Blended learning. The latter presents a much greater change in the field of education simply by adding virtual tools to classrooms. It represents, in many cases, an observable change in the instructors' and learners' approach for learning process as well as a transformational effect on learners' outcomes.

On the way to achieve the alignment of Higher Education with technology, Blended learning faces various challenges. With the common reason being the drive to respond to these challenges, the new paradigm of OC came to resolve some of the hurdles. It improves the learning process for both instructors and students, also it enables students to build and create new ideas using video lectures, quizzes, and online debates. In addition to that, an OC provides effective feedback and assessment as well as brings new methods of hybrid teaching.

\section{Literature Review}

Teaching and Learning EFL have faced an overwhelming number of limitations and many universities attempt to meet the needs of both students and teachers .In that regard, language experts and scholars saw (ICT) as supportive tool to learning and teaching EFL can encourage both students to learn and teachers to teach as it offers significant changes in EFL classroom. Furthermore, OCs as being part of the umbrella term ICT strongly provide the change which education has witnessed today. Thus, they have modified the way educational curriculum works 
mainly in literature .In that respect, many researchers tackled this subject for the goal of showing students the usefulness and the benefits of OCs as an alternative tool in learning process.

Sideris et al.,(2018), after experimenting with first-year students in computer science at the Hellenic Open University (HOU), noticed that using an OC as a preparatory course helped the students to empower and recall past knowledge, giving them a kind of readiness to start their studies easily. Besides, OC as a preparatory course seems to be the best solution to provide the students with the necessary information, and to link between the students' existing knowledge and the courses' demands because students are required to develop their knowledge before starting the academic year's courses. Furthermore, the students' enrollment was large in which most of them completed the OCs. Consequently, their attitudes were positive and they considered OC as a significant additional source of knowledge, stating that it is worth completing a project of developing and taking it as a preparatory course.

Morris (2014) stated that the students' motivation for education is changing and the process of acquiring information became easy via the Internet, mobile devices, and computers. In this regard, he explored the usage of digital technologies to promote blended learning in universities, and discussed how OCs can be developed through the better use of technology. Accordingly, the results came to illustrate that, OCs attracted and encouraged learners to achieve their learning goals by offering a well-learning design including course design and accessibility. Also, OCs offered possibilities for connection, reaction, and cooperation between learners and their educators within the course. This model contains methods of assessment and feedback to achieve the learners' outcomes.

In an attempt to bring OCs into classroom teaching of higher education, Wong et al, (2019) asserted that an OC has positive impacts on students' learning as it can help them to reach the most preferable higher education resources in the world via network and according to their own time and needs.

Jansen et al., (2020) reported on the experience of using an OC as a revision tool in modules at a Southampton university, aimed at evaluating the effectiveness of integrating such OC into traditional university modules. During their experiment, they shed light on the benefits which students can profit when undertaking a University Module in which sharing OCs is a part of the curriculum. 
After reviewing a group of experiments, Israel (2015) conducted a study on the effectiveness of integrating OCs in traditional classrooms where he noticed that the integration of OCs in traditional classroom settings was similar or slightly superior to face-to-face teaching environments.

According to Anderson et.al, (2012) literature is an essential vehicle for learning and teaching language. He argued that the use of literature in English language teaching, and the implication of literary texts may promote the development of students' skills including critical thinking, reading, writing, and speaking. More important, the use of literature for teaching could enhance the linguistic awareness and literary comprehension among students and their instructors. In this light, literature seemed to be a rich resource for language learning, and to students, it was a point which motivate them to read in English as it offered pleasure through interesting stories. However, he stated that the main challenge that teacher may face when using literature is the appropriate choice of literary texts.

The researchers' main aim in this study is to demonstrate the prominence of using an OC as a beneficial and successful tool in traditional classrooms; take into consideration, students' attitudes and learning outcomes in literature class.

\section{Rationale:}

Putting an EFL literature course into practice is not always without hurdles and challenges, in which teachers are spending much efforts and time in explaining and simplifying the literary works like novels and poems. Learners, on the other hand, are getting bored from the traditional way of learning because they like to be taught with current methods. For this reason, integrating $\mathrm{OC}$, as one of the current methods of teaching, in literature instruction can change the process of learning positively. The researchers have chosen to deal with the effect of using OCs on developing the students' performance in EFL literature courses for several reasons: first, most EFL learners are facing problems while studying literature. These struggles are a result of many facts like the lack of motivating tools and the boring method of teaching which results in passive learners. Second, many learners are tech-addicted and they like to integrate the technological devices into their studies. Third, OCs are highly used with EFL learners as they expose the participants to authentic language and provide them with 
different learning materials such as video lectures, assignments, and discussion forums. Last, several experiments have been conducted around the world to test the effectiveness of incorporating the $\mathrm{OC}$ in traditional settings, where all these experiments were successful and beneficial. Thus, introducing the OCs phenomenon in our university is considered as a revolution in the educational system and a jump to a level of creativity and self- reliance among the learners.

\section{Statement of the Problem:}

The increased presence of technology in Higher Education affects the traditional teaching environment. These days, concentrating only on traditional methods is not enough, Blended learning has also become indispensable for learning process. In that regard, OC seems to have an immense trial on student's learning and can be used as a tool to motivate both students and teachers. However, teachers are required to know how can they tie the OCs with traditional classrooms, and learners have to know how can they exploit OCs to develop their learning skills

\section{Aim of the Study:}

This study is intended to introduce and explore the concept of OC as a Model to approach the learning process, using Short Video Lectures in teaching literature. The purpose is to examine the effectiveness of OCs as educational tools in teaching EFL, and to investigate the effects of using such a tool. Accordingly, the study is to achieve certain objectives: evaluating both teachers' and students' attitudes toward the incorporation of OCs in the learning process, and evaluating the learning outcomes and needs in learning literature.

6. Research Questions: The consideration of the aforementioned points results in the formulation of three main research questions:

1- How successful is the use of OCs in the teaching of literature in EFL classrooms?

2-What are the teachers' attitudes towards the integration of OCs in their teaching process in the Amar Thelidji University? 
3rdInternational Conference on Applied Research in

EDUCATION

04-06 June,2021

Barcelona, Spain

3-What are the students' attitudes towards the integration of OCs in learning process?

To analyze this question and go deeper, two sub-research questions were raised

a) To what extent is embedding OCs in traditional classroom result in effective learning outcomes?

b) Does the use of OCs in Teaching Literature meet the needs of students in EFL classrooms?

\section{Research Methodology and Tools:}

Any research needs a suitable method to be followed as well as the correct way of collecting the data. For this reason, our research work has a descriptive-analytical nature which describes and provides many characteristics in numerical forms. In this study, both qualitative and quantitative approaches are used to investigate the impact of using OC as a teaching tool to enhance EFL learners' performance in literature classes, based on two online questionnaires addressed to EFL teachers and Second-year students randomly chosen, in the Department of English at Amar Thlelidji University. The students' questionnaire was distributed after experimenting with our case study-Second year students- with whom we experimented "four offline literature courses" taken from the edX platform.

\section{Organization of the Experiment:}

According to Brown (2013), empirical research is a "research that is based on experimentation or observation, i.e. Evidence. Such research is often conducted to answer a specific question or to test a hypothesis (educated guess)." In this research, the goal of our experiment is to introduce the concept of $\mathrm{OC}$ in our respective universities and integrate it in lectures especially literature lectures ,i.e. learning and teaching using the OC materials like Short videos. Thus, we elaborate the way the experiment is run through three stages:

\section{The Pre-course:}

At this stage, we have selected an OC from the educational platform "edX" that was launched by the Open University in 2012. "edX" is considered as one of the most leading and wellknown platform which exists nowadays and is renowned by the quality of its course contents 
3rdInternational Conference on Applied Research in

EDUCATION

04-06 June,2021

Barcelona, Spain

and the credibility of its instructions delivered by prestigious leading UK universities and institutions such as:

On 20th January, 2020, the edX platform delivered a new online course open for everyone for free, entitled "How to read a novel" instructed by the teacher of literature Alexandra Lawrie at Edinburgh University. We have chosen this course because as second-year students, they need to know how to read a novel and they have to develop their reading skills as they will be required to read novels in their coming years. In addition to that, literature represents the most important module among the other ones as well as we may also reckon that students can be highly motivated to use technological materials to foster their knowledge. All these motifs urge us to select this OC and apply it with our target sample.

On the first week, the online course covers four short -video lectures, followed by four pdfs that explain and reflect the video content. The latter was printed and distributed to the students to make the OC materials available for all of them and to help them in understanding the video content.

\section{The while-course:}

During this stage, we have devoted time to introduce the whole concept of OC including its types, features, and famous platforms. Then, we started to integrate an offline-OC in a traditional classroom (Lab) through watching the videos that we have already downloaded, reading the PDFs that were printed, and asking questions that were noted down from an OC. This process was as follow:

1) Introduction (video $02: 30 \mathrm{~min}$ )

2) Introduction to plot (pdf + video02:30 min)

3) What is the difference between the story and the plot? (Discussion)

4) Flashback and Flash-forwards (pdf + video06:03 min)

5) What are the elements that characterized the plot? (Discussion)

6) Pace (pdf + video04:35 min)

7) What is the pace? (Discussion)

8) What is the relation between pace and plot? (Discussion)

9) What makes a good book? (Discussion) 
3rdInternational Conference on Applied Research in

EDUCATION

04-06 June,2021

Barcelona, Spain

10) How would you find the OCs? (Additional question)

\section{The Post-course:}

In the very last phase of the experiment, we have conducted an online questionnaire to students using Google -Drive (Google Forms) which helps in organizing the data and transform students' answers into numerical data automatically after accomplishing partly the OC so that we can use their feedback and responses to reveal the effectiveness of OC, its influence on learning literature in EFL classes, its support to future generations to acquire knowledge using ICT and most importantly its help to tie education with the technological revolution.

\section{Questionnaires' Analysis and Interpretations}

The outcomes that are reached in this study contribute to show the needed analysis by answering the research questions in the form of charts as follows:

Teachers' Questionnaire:

Question01: Do you use any technological devices inside the classroom?

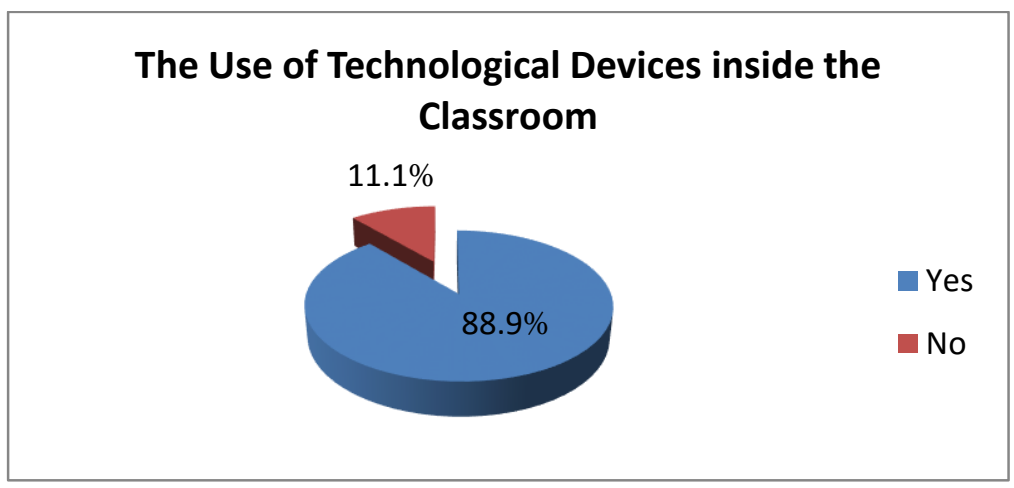

Figure 1: The Use of Technological Devices inside the Classroom

Reading the above result, it is perceived that the majority of teachers tend to use technology while teaching EFL learners. Where 08 teachers $(88,9 \%)$ reclaim that they are using the technology inside the classroom, and only one $(11,1 \%)$ states that he/she does not use technology while teaching. Thus, technology is highly integrated into the curriculum of our university. 
3rdInternational Conference on Applied Research in

EDUCATION

04-06 June,2021

Barcelona, Spain

Question02: What are the techniques you use to encourage the learning process in the classroom?

In order to know the factors that enhance the learning process, a group of suggested techniques was made for the teachers. The findings reveal that 06 teachers $(66,7 \%)$ use Questioning to encourage the learning process, 02 teachers $(22,2 \%)$ use Group work inside the classroom, and the other teacher $(11,1 \%)$ use peer -assessment as a technique to enhance the learning process. In addition to that, Debate was stated by one teacher as a technique that helps in encouraging the learning process. Thus, using different methods and techniques increases the understanding amount to students as they have different ways of understanding.

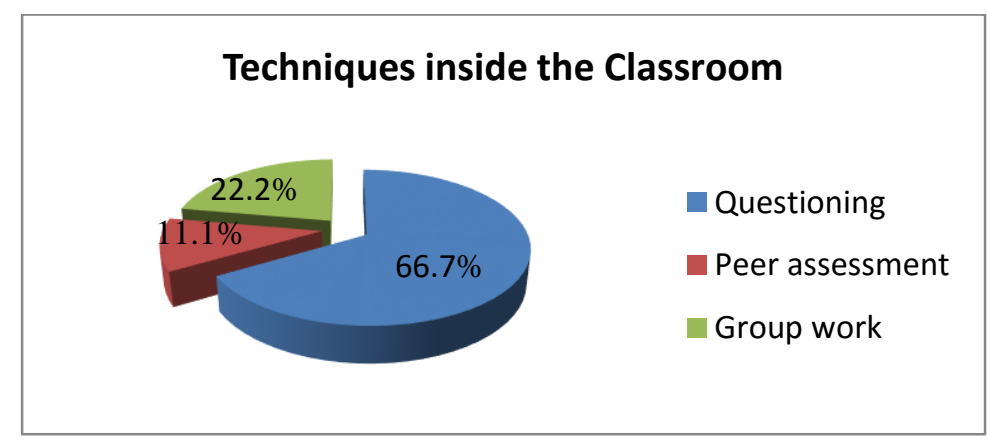

Figure 2: Teacher's Techniques inside the Classroom

Question03: What are the sources you use in preparing the lectures and lessons?

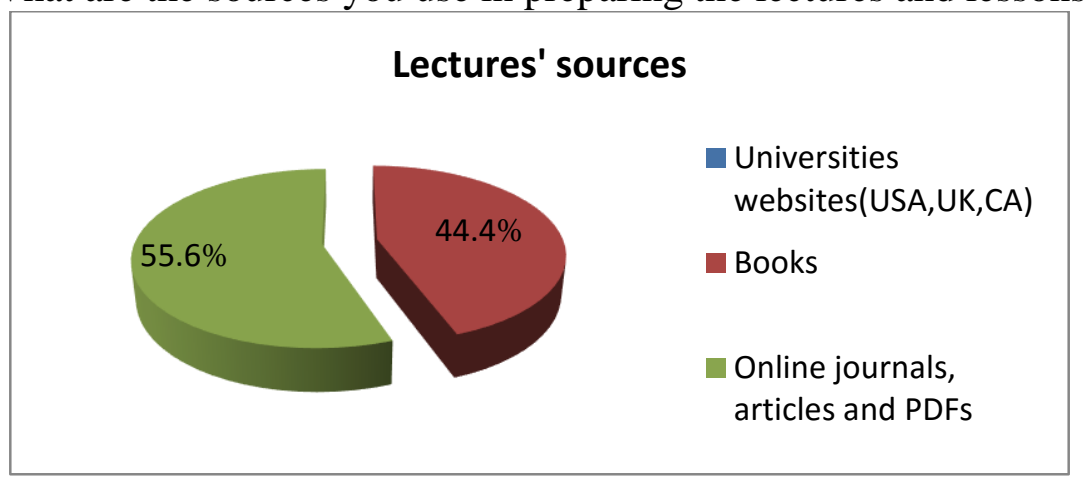

\section{Figure 3: Sources Used in Preparing the Lectures}

Since the majority of the teachers use technology inside the classroom, knowing the sources used in preparing the lectures is one of the prominent elements in our investigation. The giving graph shows that 05 teachers $(55,6 \%)$ use Online Journals, articles, and PDFs to 
prepare the lectures, while the other 04 teachers $(44,4 \%)$ use books as a means to prepare the lesson. We can notice that teachers could not make a common response towards the integration of technology since the traditional way (Books) and the technological way (online journals, articles, and PDFs) are equal in use.

Question04: The incorporation of OC helps to promote teaching and learning EFL in higher education, i.e. to provide the students with good self-directed learning skills. As a university teacher, you are for or against its integration in your teaching?

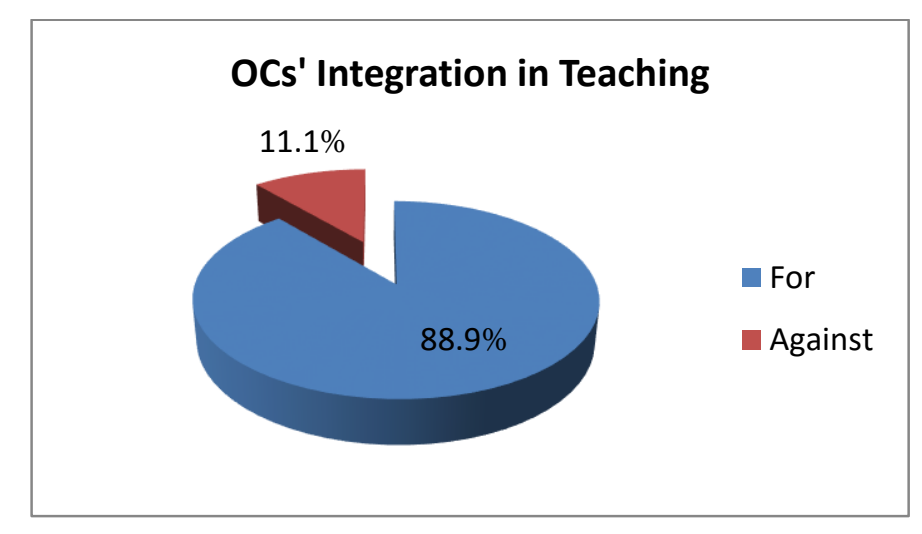

\section{Figure 4: Teacher's Attitudes towards the Incorporation of $\mathrm{OC}$ in their Teaching}

Knowing the teachers 'attitudes towards the integration of OCs in their teaching are considered as the core of our investigation. As it is illustrated above, the majority of the teachers show a positive attitude towards the integration of OCs in their teaching, in which 08 of them $(88,9 \%)$ are for the incorporation of OCs. Unlike the other one $(11,1)$ who is against such integration.

\section{Question: Why?}

The previous question was justified by the teachers in order to convince the reader. Their comments were cited as follow:

"In higher education, students should no longer act as passive receivers of knowledge, rather they should lead the learning process, and technology, of course, is a good means to provide them with self-directed learning skills. 
3rdInternational Conference on Applied Research in

EDUCATION

04-06 June,2021

Barcelona, Spain

"As a future instructional reform, OCs can be integrated only with the one condition of equipping universities, faculties, departments, and their libraries with full access to highspeed internet."

"It encourages and cultivates autonomous learning."

"Integrate OCs in traditional classrooms to make courses more constructed and varied, expose students to different ways of teaching, offer learning materials to assure online content available in classrooms, expose students to different types of learning materials."

"Additional learning tool."

"Teachers have to be creative and make use of innovations."

Thus, most of the teachers do encourage the integration of OCs as an additional learning tool in their teaching. However, efforts have to be made to supply the classrooms with technological devices to permit both teachers and students to look at some of the best universities' course contents using massive open online courses.

Question05: According to your experience and understanding, do you find an OC engaging?

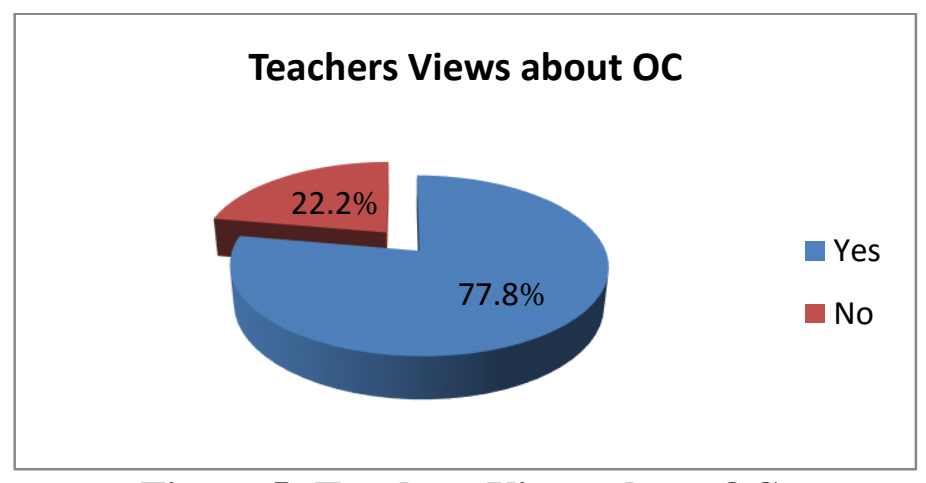

Figure 5: Teachers Views about OCs

According to the above graph, we can say that OC is highly supported by the teachers. In which 07 teachers $(77,8 \%)$ find that $\mathrm{OC}$ is engaging, but the other 02 teachers $(22,2 \%)$ do not.

Question06: As a teacher, what are the outcomes which can OCs bring to your classroom? 
3rdInternational Conference on Applied Research in EDUCATION

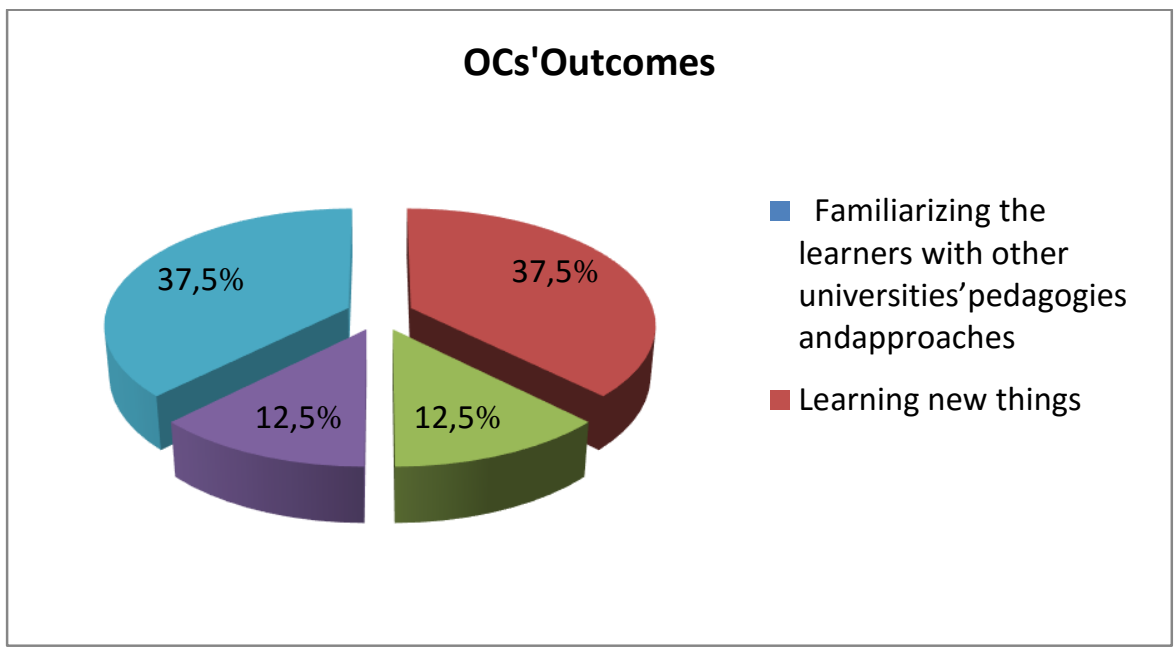

\section{Figure 6: Teachers Views about the Outcomes of OCs}

The graph presented above specifies that 03 teachers $(37,5 \%)$ reckon that OCs can help the students to learn new things. However, 03 teachers (37, 5\%) suppose that 'Adding a fresh perspective to your current role as a teacher' is one of the outcomes that OCs can bring to the classroom,01 teacher $(12,5 \%)$ thinks that OCs can expose the students to authentic language, and 01 teacher( $12,5 \%)$ states that $\mathrm{OC}$ stimulate interaction inside the classroom. Thus, the responses were different and positive, which indicates that $\mathrm{OC}$ is beneficial for the students.

Question7: How would you rate your view towards the incorporation of OCs in higher education?

\section{The Integration of OCs in Higher Education}

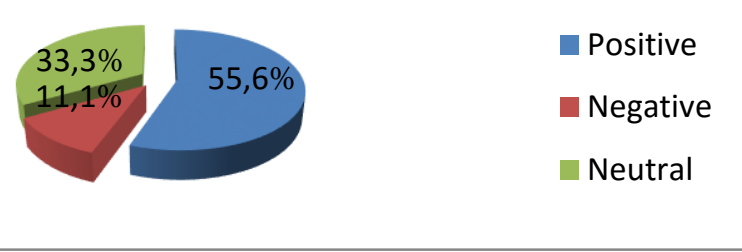

Figure 7: Teachers' Attitudes towards the Integration of OCs in Higher Education 
3rdInternational Conference on Applied Research in

EDUCATION

04-06 June,2021

Barcelona, Spain

Addressing the challenges that higher education face nowadays, an OC can be used as the best solution to promote the traditional way of teaching and learning. For this reason, teachers' attitudes towards such a decision are very important. Accordingly, the findings reveal that teachers' aspirations are positive. In which 05 teachers $(55,6 \%)$ rate their attitudes towards such incorporating as positive. However, 03 teachers $(33,3 \%)$ are neutral, and 01 teacher $(11,1 \%)$ is against the idea of the incorporation.

Question8: At last, we would be very grateful if you can provide us with some recommendations.

The teachers ' comments show that using OCs with EFL learners is helpful as it exposes them to authentic language and its learning materials encourage the students to cope with native speakers. Moreover, an OC is a new way of learning which especially attracts students' attention since they are high-tech addicts. It also encourages them to be more autonomous as they should listen, concentrate, understand and conclude because their overreliance on the teacher becomes less in OCs' courses. However, one respondent dissent from the majority, stating that the university is not yet ready to adopt such technology as students are not technologically mature.

\section{Students' Questionnaire}

Question1: What kind of struggles you face while studying literature? 


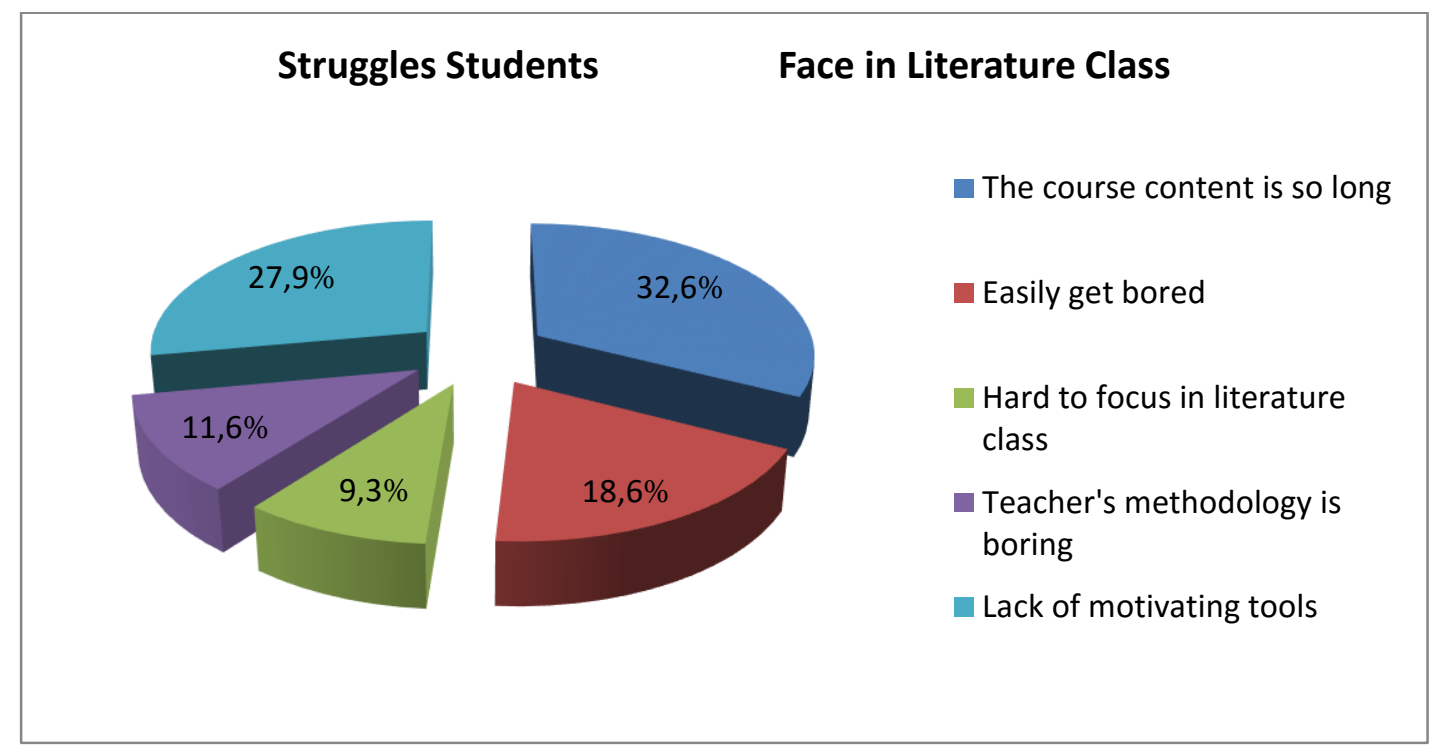

\section{Figure 1: Struggles Students Face in Literature Class}

Knowing the challenges that students may face while studying literature is considered to be part of the solution. In that case, the struggles are different and varied for each student. In the opinion of $32,6 \%$ of the participants (14), 'The course content is so long' is the reason for being uncomfortable while studying literature, whereas 12 students $(27,9 \%)$ see that 'Lack of motivation tools' can be also a reason for being uncomfortable. However, 8 students (18, $6 \%$ ) have a different view in which they easily get bored while studying literature, 5 students $(11,6 \%)$ find that the teacher's methodology is boring, and 4 students $(9,3 \%)$ cannot focus in the literature class.

Question02: What do you think of the teacher's methodology in teaching literature ? 


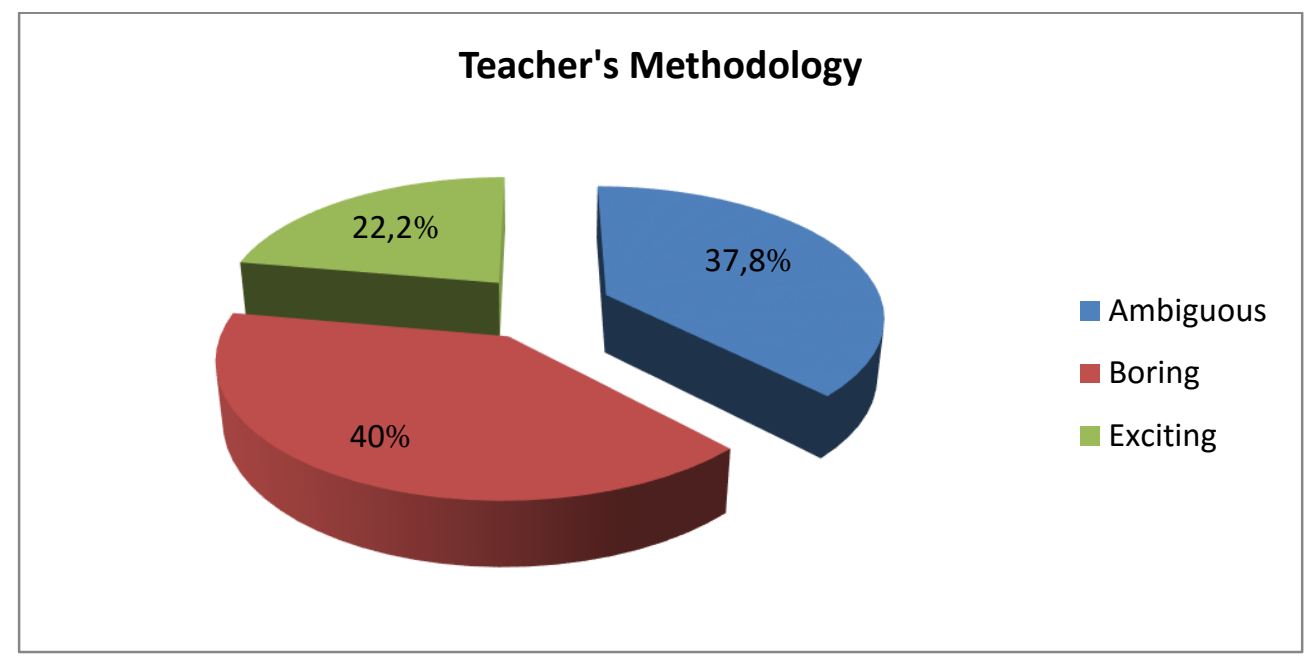

Figure 2: Students Perceptions towards Teacher's Methodology

The giving graph shows that 18 students (40\%) see the teachers' methodology in teaching literature as boring, only 10 students $(22,2 \%)$ find the teachers 'methodology to be exciting. The other $37,8 \%$ of the students (17) consider the teachers 'methodology to be ambiguous.

Question03: Do you use any application or technological tools to help you in your study?

\section{Students' Use of Technology}

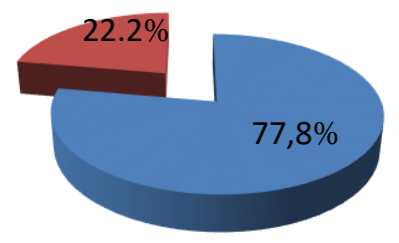

Yes

No

\section{Figure 3 : Students' Use of Technology}

Since our investigation deals with the integration of technology, it is essential to ask the students about their use of technology. Thus, the majority of the students $77,8 \%$ use technology to facilitate their learning process, and 10students $(22,2 \%)$ do not use any technological device or application to support their learning. 
3rdInternational Conference on Applied Research in

EDUCATION

04-06 June,2021

Barcelona, Spain

\section{Question: What is it?}

The student's students' comments reveal that they are using different applications to help them in their studies including, YouTube, Websites like Shmoop and Spark Notes, E-books, Phones, Google classroom, Electronic-dictionaries and English literature MCQs. Thus, we can notice that most of the students are using technology effectively.

Question04: Do OCs motivate you?

After introducing the concept of OC, 37 students $(84,1 \%)$ acknowledge that they are highly motivated when being taught with OCs. Nevertheless, 07 informants $(15,9 \%)$ believe that OCs are not motivated.

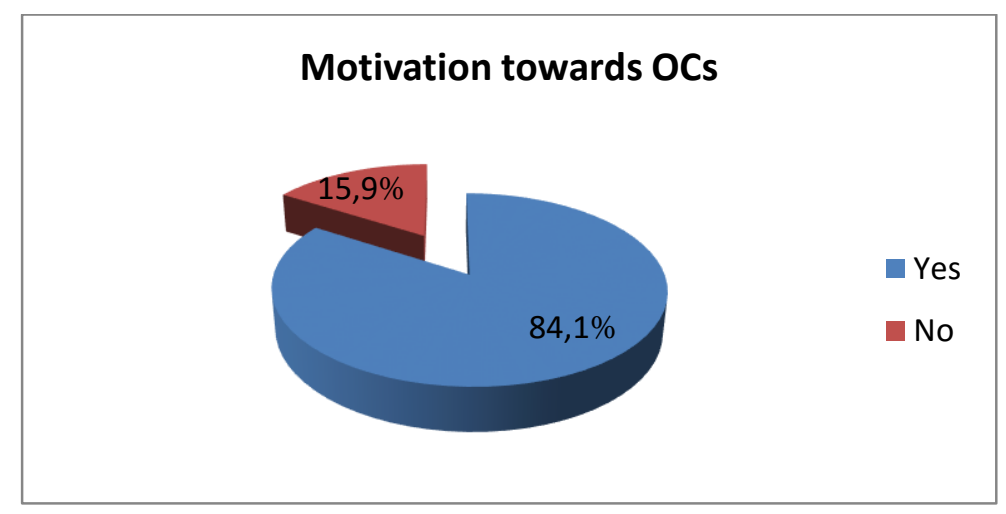

\section{Figure 04: Students Motivation towards the Use of OCs}

Question: Why?

The previous question was justified by the students to convince the reader. Some of their comments were cited as follow:

"Offers many interesting opportunities and the way of having your courses while you are relaxed at home is great."

"It motivates me to get to study and to learn more digitally even if we are in this lockdown."

"We always look for a new methodology to facilitate our study, OCs courses easily help us to get to the content."

"Because it is available every day and I can repeat what I do not understand. Moreover, I can receive the English language from the natives. " 
3rdInternational Conference on Applied Research in

EDUCATION

04-06 June,2021

Barcelona, Spain

"Because it exposes the students to various resources of learning. And it gives them the freedom. To choose the time and the place they want."

"OC is the alternative when you cannot enter the university. Its courses are done by wellfamous teachers in the world."

"Because I can choose when I study. In other words, I study when I am ready, not because I have to."

"OC is helpful, but cannot be the alternative."

Question05: Do OCs go with your expectations such as fostering language inputs and outputs, language productivity, deepening your knowledge, facilitating the course content, etc.?

\section{Students Expectations about OCs}

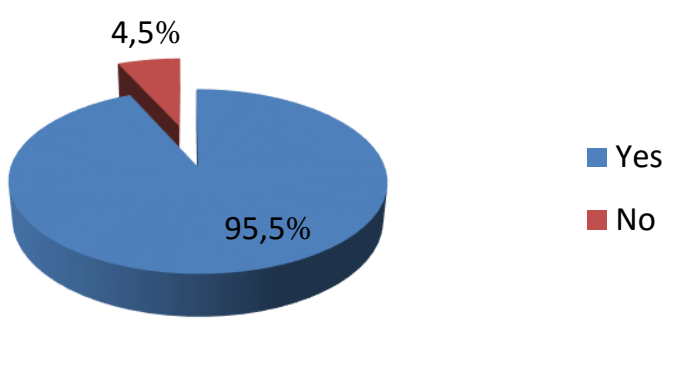

\section{Figure 05: Students Expectations about OCs}

After supposing that OCs can foster language inputs and outputs, language productivity, and facilitate the course content, the majority of the students agreed with such expectations; in which 42 students $(95,5 \%)$ respond by yes. However, a few students $(4,5 \%)$ respond by no. Thus, OCs is highly accepted by the students.

Question06: According to the previous experiment, would you like OCs to be integrated in teaching literature? 
3rdInternational Conference on Applied Research in

EDUCATION

04-06 June,2021

Barcelona, Spain

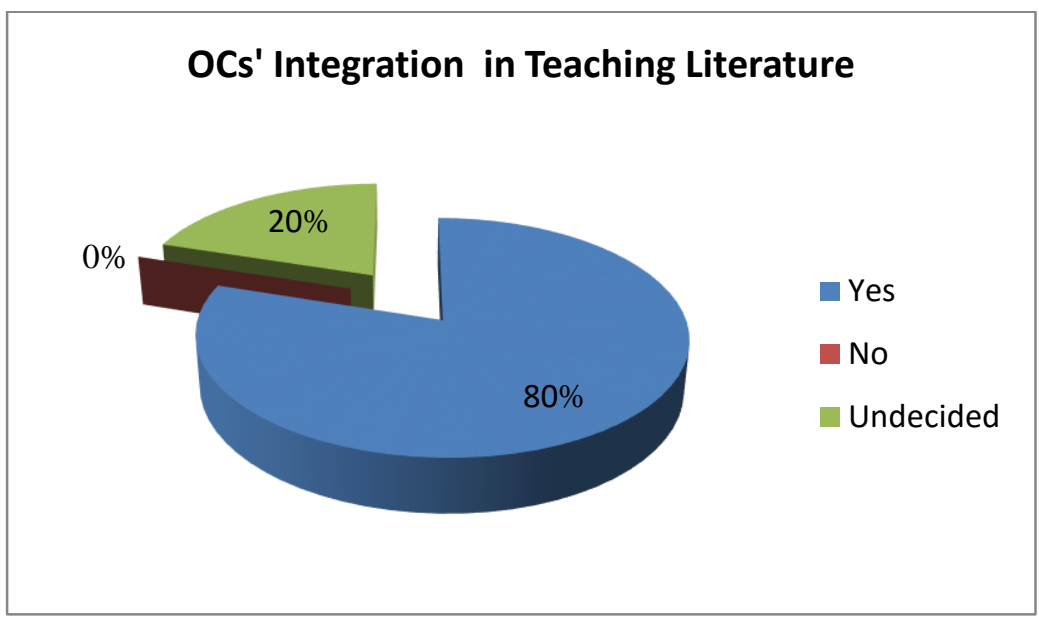

Figure 6:Students'Attitudes towards the Integration of OCs in Teaching Literature

According to the above graph, most of the students (80\%) want OCs to be integrated in a literature class as they have a course in literature online, but 09 students (20\%) do not decide about the idea of the integration.

Question07: Do you prefer the learning through OCs or the traditional method?

\section{Ways of Learning}

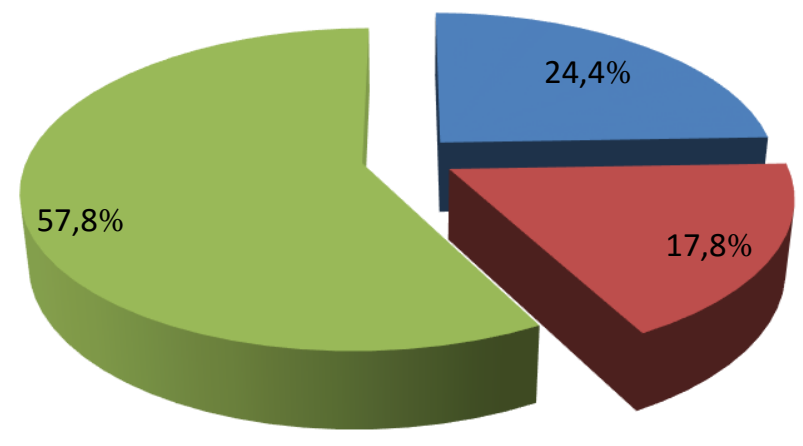

- The traditional way

Both

\section{Figure 07: Students Opinions about the Way of Learning}

Asking the students about the way they prefer to learn is the cornerstone of our investigation. In which 26 students $(57,8 \%)$ prefer to learn using both OCs and the traditional way,11 students $(24,4 \%)$ like the OC way, and only 08 students $(17,8 \%)$ prefer to learn through the traditional way. Thus, the integration of technology seems to be suitable for the students. 
3rdInternational Conference on Applied Research in EDUCATION

Question 08: What is the skill which OCs promote?

\section{Enhanced Skills in an OC}

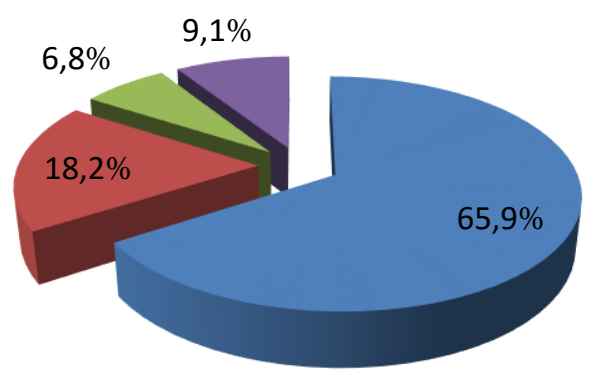

- Listening

- Speaking

Reading

Writing

\section{Figure8: Enhanced Skills in OCs}

The giving graph specifies that 29 students $(65,9 \%)$ reckon that listening is primarily enhanced by OC, followed by speaking $(18,2 \%)$, writing $(9,1 \%)$, and reading $(6,8 \%)$.

Question 09: Do OCs expose you to an authentic language? (Real language)

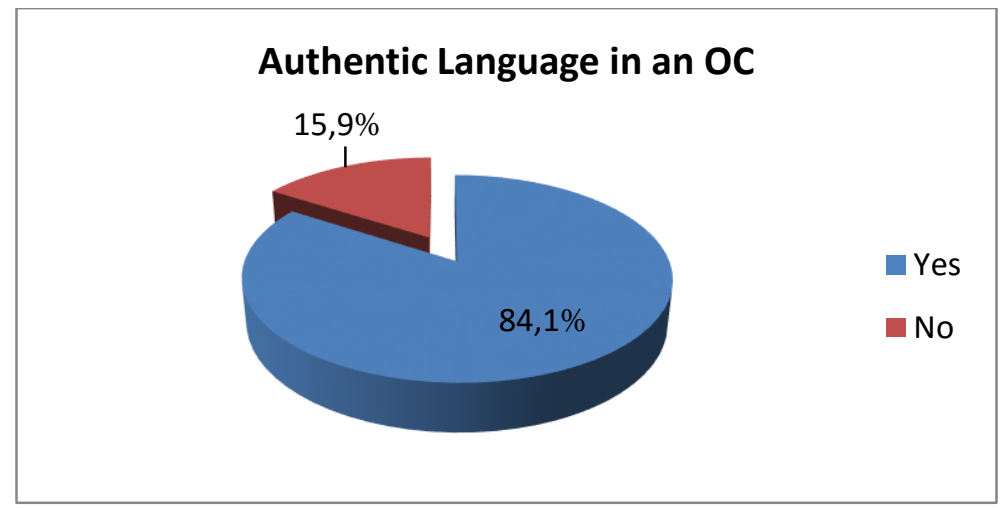

Figure 09: Authentic Language in an OC

Since OCs are delivered by native speakers, most of the students $(84,1 \%)$ find that OC exposes them to authentic language. Unlike, 07 students $(15,9 \%)$ disagree with the idea.

Question 10: What are your suggestions to teachers about OCs implementation in classroom?

The last analysis is concerned with the students' suggestions to teachers about OCs use in classrooms. From their comments, we have taken some relevant ones. They are as follows: 
"It's a good way to study, but we need a good internet to be able to use it well. We students are not used to study in such a way, so teachers need to make students use it from time to time."

"I do prefer the OC and recommend it because I tried a lot of websites and app but unfortunately they didn't work for me or the other students so I will say to keep using it and post some new course tasks."

“The OCs' incorporation in the Algerian university's classrooms will be a revolution in our educational system and a jump to another level of creativity and self- reliability among learners."

"The integration of technology in the teaching process plays a vital role that impacts both teachers and students. Yet, the use of such a method in the classroom will help students to learn effectively and develop their skills and experiences."

"It will good and helpful of course, but not to rely totally and heavily on this method."

Students have revealed that OCs got them to discover a new way of learning; this educational method allows them to be involved and enhance their learning skills like listening and speaking. Thus, they do encourage the teachers to use OCs in classrooms.

\section{Conclusion}

Along the experiment, we have deduced through our data collection instruments that teachers and students prefer to harmonize between the traditional way of teaching and the modern way; they showed an optimistic views regarding the integration of an OC within teaching/learning literature as they could not deny the fact that the traditional way of teaching still matters. Therefore, OCs as a teaching tool, can have positive effects on students, and encourage them to develop their achievements in literature classes; and helps the students, too, to reach their teaching goals. All in all, the integration of OCs provides an opportunity for teachers and students to engage in a virtual learning environment and impact the teaching and learning process effectively. As for the future, we recommend future researchers to experiment an OC and to register for it in one of the reputable platforms like FutureLearn , edX , or Coursera to experience really the self-direct learning process through ICT.Also to become familiar with MOOCs Massive Open Online Courses. 
3rdInternational Conference on Applied Research in

EDUCATION

04-06 June,2021

Barcelona, Spain

\section{References}

Allen, I. E. \& Seaman, J. (2013). Changing Course: Ten years of tracking online education in the United States. Babson Survey Research Group. Retrieved from http://www.onlinelearningsurvey.com/reports/changingcourse.pdf

Anderson, T., \& McGreal, R. (2012). Disruptive pedagogies and technologies in universities. Education Technology and Society, 15(4), 380-389.

Bobkina, J., \& Dominguez, E. (2014). The use of literature and literary texts in the EFL classroom; between consensus and controversy. International Journal of Applied Linguistics \& English Literature, 3(2), 248-260. doi:10.7575/aiac.ijalel.v.3n.2p.248

Brown, S. (2013). Back to the future with MOOCs?. ICICTE 2013 Proceedings, 237-246.

Carvalho, P. F., Sana, F., \& Yan, V. X. (2020). Self-regulated spacing in a massive open online course is related to better learning. NPJ science of learning, 5(1), 1-7.

Hendriks, R.A., De Jong, P.G.M., Admiraal, W.F., \& Reinders, M.E.J. (2019). Teaching modes and social-epistemological dimensions in medical massive open online courses: Lessons for integration in campus education. Medical Teacher, 41(8), 917-926.

Hollands, F. \& Tirthali, D. (2014) MOOCs: Expectations and reality .New York: Columbia University Teachers ${ }^{e e}$ College, Center for Benefit-Cost Studies of Education.

Israel, M.J. (2015). Effectiveness of integrating MOOCs in traditional classrooms for undergraduate students. International Review of Research in Open and Distributed Learning, 16(5), 102-118. DOI: https://doi.org/10.19173/irrodl.v16i5.2222

Jansen, R. S., van Leeuwen, A., Janssen, J., Conijn, R., \& Kester, L. (2020). Supporting learners' self-regulated learning in Massive Open Online Courses. Computers \& Education, $146,103771$. 
3rdInternational Conference on Applied Research in

EDUCATION

04-06 June,2021

Barcelona, Spain

Morris, N.P. (2014). How digital technologies, blended learning will impact the future of higher education. International Conference e-Learning, 8(5), 401-404.

Sideris, D., Karakatsoulis, D., Kalles, D., \& Xenos, M. (2018). Applying an online Course as a preparatory course for first -year students in computer science. Proceedings of EDULEARN18 Conference, 5806-5811.

Wong, J., Khalil, M., Baars, M., de Koning, B. B., \& Paas, F. (2019). Exploring sequences of learner activities in relation to self-regulated learning in a massive open online course. Computers \& Education, 140, 103595.

Wu,K.H. (2016). How literature circles support EFL college students ${ }^{e e}$ literary and literacy learning in a Children 's and Adolescent literature course. Literacy Information and Computer Education Journal (LICEJ), 7(3), 2347-2352. Retrieved from https://www.researchgate.net/publication/326865426 